\title{
JUÍZO UNIVERSAL DA FALÊNCIA E EXECUÇÕES DE CRÉDITOS FISCAIS
}

Jadir Rafael da Silva Filho, Edson Freitas de Oliveira

Faculdades Integradas "Antônio Eufrásio de Toledo". Curso de Direito, Presidente Prudente - SP. E-mail: jadir rafael@hotmail.com

\section{RESUMO}

O presente artigo surgiu em razão de uma discussão acadêmica da possibilidade do juízo da falência ter competência para julgar ações fiscais. Trazendo reflexões sobre as mudanças decorrentes da entrada em vigor da Lei $\mathrm{n}^{\circ}$ 11.101/05. Também aborda as peculiaridades do processo de falência, como a aplicação do princípio da universalidade do juízo falimentar, processando e julgando todas as ações em que houver interesse da massa. Intenta abordar, a vis attractiva, seus efeitos e exceções, com foco nas execuções fiscais. Por fim, demonstra a inversão da classificação de credores em decorrência dos efeitos causados pelas exceções aos princípios da falência e a solução dada pela jurisprudência para o caso.

Palavras-chave: Universal. Falência. Créditos. Fiscais. Credores.

\section{UNIVERSAL COURT OF BANKRUPTCY AND EXECUTIONS OF TAX CREDITS}

\begin{abstract}
This article appeared in the grounds of a scholarly discussion of the possibility of bankruptcy court having jurisdiction over tax claims. Bringing reflections on the changes resulting from the entry into force of Law No. 11,101 / 05. It also addresses the peculiarities of the bankruptcy process, as the principle of universality of bankruptcy court, suing and judging all actions in which there is interest from the mass. Attempts to address the attractiva vis, its effects and exceptions, focused on tax foreclosures. Finally, the inversion shows the classification of creditors due to the effects caused by exceptions to the principles of bankruptcy and the solution given by law to the case.
\end{abstract}

Keywords: Universal. Bankruptcy. Credits. Tax. Creditors. 


\section{INTRODUÇÃO}

Com a entrada em vigor da Lei 11.101/05, denominada Lei de Recuperação e Falência, houve um grande avanço deste instituto na legislação brasileira. Entretanto, tal diploma legal mencionado levantou discussões sobre a revogação ou não do artigo 187 do Código Tributário Nacional.

A primeira parte deste trabalho trata do processo de falência e suas peculiaridades, demonstrando sua complexidade e que seus desdobramentos devem ser previstos, evitando ao máximo a afetação do restante do mercado, para que a importância do instituto seja comprovada.

Na segunda parte, abordam-se as consequências da interpretação sobre a revogação ou não do artigo 187 do CTN e a incompatibilidade com as intenções da LF, principalmente quanto ao não cumprimento da ordem de classificação de credores.

O objetivo do trabalho foi verificar se os problemas decorrentes da exceção ao princípio da atração nas ações de falência, foram sanados com o posicionamento tomado pela jurisprudência.

\section{METODOLOGIA}

Para a realização deste trabalho, foram utilizados os métodos dialético (para desconstruir e recompor os princípios da falência), dedutivo (para comprovar as consequências da inversão da classificação de credores) e fenomenológico (para se reconhecer que essa questão prejudica o sistema da legislação falimentar, devendo o problema ser resolvido).

\section{ATRAÇÃO DO JUÍZO FALIMENTAR E SUA INDIVISIBILIDADE}

A estrutura de um processo de falência se mostra complexa quando comparada com outros processos convencionais. Isto ocorre pelo fato de que são envolvidos neste processo vários órgãos e credores da falida.

Para assegurar à ordem econômica, que é um princípio fundamental garantido pela Constituição Federal no seu artigo 170, a lei de falência determina no seu artigo $76^{1}$ que o juízo da falência é indivisível. Conforme Amador Paes de ALMEIDA (2010, p. 126):

[...] é, pois, no juízo da falência que se processam o concurso creditório, a arrecadação dos bens do falido, a habilitação dos créditos, os pedidos de restituição e todas as ações, reclamações e negócios de interesse da massa, dai decorrendo a sua indivisibilidade.

\footnotetext{
${ }^{1}$ Art. 76. O juízo da falência é indivisível e competente para conhecer todas as ações sobre bens, interesses e negócios do falido, ressalvadas as causas trabalhistas, fiscais e aquelas não reguladas nesta Lei em que o falido figurar como autor ou litisconsorte ativo. 
O juízo falimentar tem como qualidade a vis attractiva, atraindo as ações em curso para o magistrado responsável pela falência, sendo esse o juízo exclusivo. Isto deve ocorrer para proteger o objetivo da falência, já que esta é uma execução concursal. Com efeito, caso não houvesse esta tramitação de todas as execuções no mesmo juízo, ocorreria várias execuções individuais ao mesmo tempo, um grande volume de processos, a existência de uma competição entre todos os credores com a finalidade de receber primeiro, além do risco de decisões conflitantes. Por estas razões que o processo de falência existe, permitindo que todos os credores tenham possibilidade de executar suas dívidas no mesmo juízo.

Para Fabio Ulhoa COELHO (2013, p. 274):

[...] isto significa que todas as ações referentes aos bens, interesses e negócios da massa falida serão processadas e julgadas pelo juízo perante o qual tramita o processo de execução concursal por falência. É a chamada aptidão atrativa do juízo falimentar, ao qual conferiu a lei a competência para conhecer e julgar todas as medidas judiciais de conteúdo patrimonial referente ao falido ou à massa falida.

O princípio da universalidade do juízo falimentar busca assegurar a máxima de que o patrimônio do devedor é a garantia do credor. O tratamento da lei é igualitário no sentido de possibilitar a todos os credores cobrarem seus créditos, independente da natureza deste, reunindo todos os bens da massa falida. Entretanto, a lei estabelece uma classificação dos credores que será abordado mais à frente. Como toda regra permite exceções, trataremos agora das ações que não são atraídas pelo juízo da falência.

\section{AS EXCEÇÕES A UNIVERSALIDADE DO JUÍZO FALIMENTAR}

A atração do juízo falimentar é uma regra, que comporta exceções pré-estabelecidas em lei, como as elencadas no artigo 76 da LF, e tem como objetivo identificar e delimitar as situações nas quais a regra da universalidade será relativizada. Deste modo, excluem-se da competência do juízo falimentar as ações onde a falida é autor ou litisconsorte ativo, tomando por base o artigo $94^{2}$ do Código de Processo Civil, sendo competente o foro do domicilio do réu.

As ações em que a união for parte não são atraídas ao juízo falimentar, por estar regulada expressamente no artigo 109 inciso $l^{3}$ da Constituição Federal, devendo ser respeitada a hierarquia das normas.

\footnotetext{
${ }^{2}$ Art. 94. A ação fundada em direito pessoal e a ação fundada em direito real sobre bens móveis serão propostas, em regra, no foro do domicílio do réu.

${ }^{3}$ Art. 109. Aos juízes federais compete processar e julgar: I - as causas em que a União, entidade autárquica ou empresa pública federal forem interessadas na condição de autoras, rés, assistentes ou oponentes, exceto as de falência, as de acidentes de trabalho e as sujeitas à Justiça Eleitoral e à Justiça do Trabalho;
} 
Da mesma forma, com base no artigo 114 da Constituição Federal, a LF torna exceção à regra as ações trabalhistas. Portanto, estas ações tramitarão no juízo trabalhista.

Também estão previstas, como exceção, as execuções tributárias, com base no artigo $187^{4}$ do CNT. Esta exceção cria uma situação de possível burla da classificação de credores.

\section{A CLASSIFICAÇÃO DE CREDORES}

A decretação da falência move a máquina judiciária para que todas as obrigações daquela empresa, agora falida, sejam cumpridas, ocorrendo uma execução de um devedor por vários credores. Contudo, são raras as hipóteses em que os bens da massa falida pagarão seu saldo devedor. Dessa forma, o administrador judicial deve pagar com os bens da massa os credores, respeitando uma classificação que busca assegurar um pagamento justo.

Gladston MAMEDE (2006, p. 565) afirma sobre a classificação de credores:

[...] eis as bases do princípio da par conditio creditorum, ou seja, da condição paritária (igualitária) entre os credores: dar a todos um mesmo tratamento, compartilhando os ônus da quebra, quero dizer, os ônus de terem o mesmo devedor e não poder ele adimplir todas as suas obrigações.

Esta igualdade consiste em todos os credores terem condições de cobrar o que lhes é devido, e não de receberem o mesmo valor, pois nesta ultima hipótese, o credor com maior credito receberia o mesmo valor de um credor com o crédito menor, mas a consequência seria de que aquele credor com o crédito menor receberia todo o valor da dívida, enquanto o credor maior não iria receber nem a metade do valor devido.

Ensina Fabio Ulhoa COELHO (2013, P. 377):

[...] não é injusta a hierarquização em desfavor da generalidade dos empresários, já que eles normalmente têm condições de se prevenir contra a insolvência da devedora, seja por meio de taxas de risco embutidas nos preços e juros, seja pela existência de codevedores, por fiança ou aval.

A ordem de classificação de credores, que deve ser respeitada pelo administrador judicial, está no artigo 83 da LF . Este artigo tem influência de alguns dispositivos legais, tais como o artigo

\footnotetext{
${ }^{4}$ Art. 187. A cobrança judicial do crédito tributário não é sujeita a concurso de credores ou habilitação em falência, recuperação judicial, concordata, inventário ou arrolamento. Parágrafo único. O concurso de preferência somente se verifica entre pessoas jurídicas de direito público, na seguinte ordem: I - União; II - Estados, Distrito Federal e Territórios, conjuntamente e pró rata; III - Municípios, conjuntamente e pró rata. ${ }^{5}$ Art. 83. A classificação dos créditos na falência obedece à seguinte ordem: I - os créditos derivados da legislação do trabalho, limitados a 150 (cento e cinquenta) salários-mínimos por credor, e os decorrentes de acidentes de trabalho; II - créditos com garantia real até o limite do valor do bem gravado; III - créditos tributários, independentemente da sua natureza e tempo de constituição, excetuadas as multas tributárias; IV - créditos com privilégio especial, a saber a) os previstos no art. 964 da Lei no 10.406, de 10 de janeiro de 2002; b) os assim definidos em outras leis civis e comerciais, salvo disposição contrária desta Lei; c) aqueles a cujos titulares a lei confira o direito de retenção sobre a coisa dada em garantia; $V$ créditos com privilégio geral, a saber: a) os previstos no art. 965 da Lei no 10.406, de 10 de janeiro de 2002; b) os previstos no parágrafo único do art. 67 desta Lei; c) os assim definidos em outras leis civis e comerciais, salvo disposição contrária desta Lei; VI - créditos quirografários, a saber: a) aqueles não previstos nos demais incisos deste artigo;
} 
$449^{6}$ da CLT e $186^{7}$ do CTN. É importante destacar que a mudança da legislação em 2005 alterou a posição dos créditos tributários, que antes ocupava a $2^{\circ}$ colocação, e atualmente figura na $3^{\circ}$ posição, sendo a $2^{\circ}$ dos créditos com garantias reais.

O fato destes créditos tributários não serem atraídos para o juízo da falência cria o risco de serem pagos antes dos credores trabalhistas e com garantia real, na hipótese da ação individual ter o tramite processual mais ágil que a execução coletiva, não sendo respeitada a classificação de credores.

\section{A SOLUÇÃO DADA PELA DOUTRINA E JURISPRUDÊNCIA}

Para a problemática levantada, Fabio Ulhoa COELHO (2013, p. 341) traz, como solução nesta hipótese, terá o preterido direito crediticio contra aquele que recebeu indevidamente, no valor do que lhe caberia, segundo a natureza de seu crédito e as forças da massa.

A solução dada pelo autor pode ser aplicada nos casos em que já ocorreu a inversão no pólo da classificação de credores. Entretanto, o ideal é que essa inversão seja evitada. Conforme entendimento jurisprudencial demostrado pela decisão publicada em 28/09/2009 pelo STJ no AgRg no Ag 1115891 / SP, tendo como Ministro Relator MAURO CAMPBELL MARQUES:

PROCESSUAL CIVIL. TRIBUTÁRIO. AUSÊNCIA DE IMPUGNAÇÃO ESPECÍFICA AOS FUNDAMENTOS DA DECISÃO AGRAVADA. INCIDÊNCIA DA SÚMULA N. 182/STJ. EXECUÇÃO FISCAL. PENHORA DE BEM. POSTERIOR DECRETAÇÃO DE FALÊNCIA. PRETENSÃO DE ARREMATAÇÃO DO BEM PENHORADO NO FEITO EXECUTIVO. SÚMULA N. 44 DO EXTINTO TFR E INTERPRETAÇÃO SISTEMÁTICA DOS ARTS. 29 DA LEI N. 6.830/80 E 186 E 187 DO CTN. GARANTIA DE OBSERVÂNCIA DA ORDEM LEGAL DE PREFERÊNCIA ENTRE OS CREDORES DA MASSA FALIDA

A posição da jurisprudência, de que o montante arrecadado na penhora deve ser entregue a massa falida, possibilita o cumprimento da ordem de pagamento dos credores. Posteriormente, os créditos fiscais serão satisfeitos, conforme estejam inscritos no quadro geral de credores.

\section{CONCLUSÃO}

Em que pese serem os créditos tributários de suma importância para a sociedade, pois estes são revertidos em benefício dela própria, e estar expressamente disposto no artigo 187 que as execuções fiscais não se submetem a universalidade do juízo falimentar, o fato é que tal

\footnotetext{
b) os saldos dos créditos não cobertos pelo produto da alienação dos bens vinculados ao seu pagamento; c) os saldos dos créditos derivados da legislação do trabalho que excederem o limite estabelecido no inciso I do caput deste artigo; VII - as multas contratuais e as penas pecuniárias por infração das leis penais ou administrativas, inclusive as multas tributárias; VIII - créditos subordinados, a saber: a) os assim previstos em lei ou em contrato; b) os créditos dos sócios e dos administradores sem vínculo empregatício.

${ }^{6}$ Art. 449 - Os direitos oriundos da existência do contrato de trabalho subsistirão em caso de falência, concordata ou dissolução da empresa.

7 Art. 186. O crédito tributário prefere a qualquer outro, seja qual for sua natureza ou o tempo de sua constituição, ressalvados os créditos decorrentes da legislação do trabalho ou do acidente de trabalho.
} 
exceção perde aplicação, já que lei nova revoga lei velha, e, portanto, a Lei de Recuperação e Falência revoga tacitamente o Código Tributário Nacional ao regular matéria específica de forma diferente.

A jurisprudência entende que o valor arrecadado da venda do bem penhorado deve ser entregue a massa falida, para que se prossiga o pagamento na ordem dos créditos inscritos. A problemática é que o valor aferido com a venda de um bem, pode ser menor, do que se este mesmo bem, fosse vendido em conjunto com outras peças fundamentais ao desenvolvimento daquela atividade.

Assim, o artigo 76 da LF é, em parte, contrário às intenções do corpo normativo que pertence, devendo sua interpretação seguir os princípios e objetivos trazidos pela lei.

Por fim, o artigo $6^{\circ} \S 7$ da LF assegura a não suspenção das execuções fiscais apenas na recuperação judicial, não tratando das situações de falência. Resta verificar a intenção do legislador, pois, na maioria das vezes, a exceção a uma regra é trazida pelo próprio texto de lei, cabendo, neste caso, a interpretação de que, como o artigo não trata da falência, nestas hipóteses não ocorre a suspenção das execuções fiscais.

\section{REFERÊNCIAS}

ALMEIDA, Amador Paes de. Curso de falência e recuperação de empresa. 25. ed., rev. e atual. São Paulo: Saraiva, 2010.

AMARO, Luciano. Direito tributário brasileiro. 16. ed. São Paulo: Saraiva, 2010.

BRASIL. Constituição (1988). Constituição da República Federativa do Brasil. Brasília, DF: Senado, 1988.

. Lei $n^{\circ} 5.172$ (1966). Sistema Tributário Nacional. Brasília, DF: Senado, 1966.

. Lei $n^{\circ} 11.101$ (2005). Recuperação Judicial, a Recuperação Extrajudicial e a Falência do

Empresário e da Sociedade Empresária. Brasília, DF: Senado, 2005.

. Supremo Tribunal de Justiça. AGRAVO REGIMENTAL NO AGRAVO DE INSTRUMENTO ${ }^{\circ}$

1115891, Brasília, 15 de setembro de 2009. Disponível em:

http://www.stj.jus.br/SCON/jurisprudencia/toc.jsp?tipo visualizacao=null \&processo=1115891\&b=

ACOR\&thesaurus=JURIDICO. Acesso em: 29 ago. 2014.

CARVALHO, Paulo de Barros. Curso de direito tributário. 22. ed. São Paulo: Saraiva, 2010.

COELHO, Fábio Ulhoa. Curso de direito comercial: direito de empresa. 14. ed., rev. e atual. São Paulo: Saraiva, 2013. v. 3.

FAZZIO JÚNIOR, Waldo. Manual de direito comercial. 11. ed. São Paulo: Atlas, 2010. 
MAMEDE, Gladston. Falência e recuperação de empresas. São Paulo: Atlas, 2006. (Direito empresarial brasileiro; 4) 